Fetal Diagnosis
Fetal Diagn Ther 2009;25:230-233

DOI: $10.1159 / 000221378$
Received: January 30, 2008

Accepted after revision: July 30, 2008

Published online: May 28, 2009

\title{
Prevention of Preterm Delivery with Periodontal Treatment
}

\author{
Tibor Novák ${ }^{a}$ Márta Radnai ${ }^{b}$ István Gorzób Edit Urbán $^{c}$ Hajnalka Orvos ${ }^{a}$ \\ József Eller ${ }^{d}$ Attila Pála \\ ${ }^{a}$ Department of Obstetrics and Gynaecology, ${ }^{b}$ Faculty of Dentistry and Orofacial Surgery, \\ ${ }^{c}$ Institute of Clinical Microbiology and d Department of Medical Informatics, University of Szeged, Szeged, Hungary
}

\section{Key Words}

Periodontitis · Preterm delivery · Periodontal treatment

\begin{abstract}
Objective: To demonstrate the role of periodontal treatment (PT) in the prevention of preterm delivery (PD). Methods: A comparative prospective study of two groups of pregnant women with threatening PD was carried out at the Department of Obstetrics and Gynaecology of the University of Szeged: group A $(n=39)$ comprised patients who were merely examined dentally for periodontitis, and group $B$ ( $n=44$ ) consisted of patients who received periodontal treatment during pregnancy. Results: Periodontitis was identified in 19 cases (48.7\%) in group A and in 18 cases $(40.9 \%)$ in group $B$. The mean birth weight of the newborns was significantly higher in group $B(3,009.1 \mathrm{~g})$ than in group $A(2,580.8 g ; p=0.007)$. The rate of premature birth was significantly lower in the group who received PT $(p=0.012$, odds ratio $=3.5,95 \%$ confidence interval $=1.38-8.86)$. Conclusions: The PT of pregnant women can decrease the rate of premature birth and consequently lead to a better neonatal health outcome.

Copyright $\odot 2009$ S. Karger AG, Basel
\end{abstract}

\section{Introduction}

In many countries, premature birth is a great problem in relation to health, economy, society and family. Premature newborns are more prone to different illnesses such as neuromotor abnormalities, lung diseases or cerebral palsy. Early death is more frequent than in term newborns.

Approximately 95,000 live births are registered each year in Hungary, some $8-9 \%$ of which involve preterm delivery (PD), defined as the occurrence of labour before the 37 th gestational week.

The rate of $\mathrm{PD}$ at the Department of Obstetrics and Gynaecology of the University of Szeged, a tertiary-care unit in the south-east of Hungary, is rather high (approx. $13-16 \%)$.

Various studies since the 1990s have demonstrated a relationship between PD and periodontal disease. Many authors have reported that a severe, generalized infection of the periodontium is a possible risk factor for PD [1-9]. However, others have not found such evidence [10]. Some studies indicated that periodontal treatment (PT) significantly reduces the risk of $\mathrm{PD}$ and preterm low birth weight [11-13].

The aim of the present study was to investigate whether or not there is an association between the periodontal

\footnotetext{
Dr. Tibor Novák

University of Szeged, Department of Obstetrics and Gynaecology Semmelweis u. 1, HU-6725 \$zeged (Hungary)

Tel. +3662545491, Fax +3662545711

E-Mail novakta@freemail.hu or novobgyn@invitel.hu
} 
Table 1. The mean gestational age and the mean newborn weights at delivery, the 5-min Apgar score, the umbilical cord vein pH data and the rate of prematurity

\begin{tabular}{llllll}
\hline & $\begin{array}{l}\text { Gestational age } \\
\text { at delivery, weeks }\end{array}$ & $\begin{array}{l}\text { Newborn weight } \\
\mathrm{g}\end{array}$ & $\begin{array}{l}\text { 5-min } \\
\text { Apgar score }\end{array}$ & $\begin{array}{l}\text { Umbilical cord } \\
\text { vein pH }\end{array}$ & $\begin{array}{l}\text { Rate of prematurity } \\
\%\end{array}$ \\
\hline Group A $(\mathrm{n}=39)$ & $36.08 \pm 2.757$ & $2,580.8 \pm 668.5$ & $9.44 \pm 1.071$ & $7.233 \pm 0.1057$ & 53.8 \\
Group B $(\mathrm{n}=44)$ & $37.52 \pm 1.923$ & $3,009.1 \pm 711.3$ & $9.68 \pm 0.909$ & $7.268 \pm 0.0831$ & 25 \\
p value & 0.011 & 0.007 & 0.127 & 0.083 & 0.012 \\
\hline
\end{tabular}

status of pregnant women and PD under conditions of prenatal care in Hungary. We also tested whether or not professional PT has a beneficial effect on the prevention of $\mathrm{PD}$, which consequently may improve the perinatal outcome.

\section{Materials and Methods}

A total of 83 patients were enrolled into the study; all were volunteers due to deliver at the Department of Obstetrics and Gynaecology in Szeged. They were informed in detail about the aim of the study and signed a detailed consent form which was approved by the Ethics Committee for dental, obstetric and microbiological investigations. With a view to homogeneity of the groups, only primigravida-primiparous, singleton, healthy pregnancies were selected for this study. The patients were nonsmokers and were selected so that the role of additional risk factors for PD such as socio-economic status or a poor nutritional state was nonsignificant. For this reason, the overall number of patients was relatively low, but only those who met the severe criteria for selection were enrolled.

Before the study, a sample size calculation was performed which related to birth weight assessment and time of gestation. For a 2-sample $t$ test with $90 \%$ test power and 0.05 error rate, assuming a 500-gram birth weight difference at $650 \mathrm{~g}$ standard deviation (SD), $\mathrm{n}=37$ was the necessary case number, and to prove a 1.5 -week difference in delivery time, at 2 weeks $S D$, the required minimal sample size was $\mathrm{n}=39$.

The patient selection for the two groups was randomized, based on the throw of even or odd numbers with a dice. The patients were familiarized with the consent form before the random selection procedure was performed. The study period was between January 1, 2006, and December 31, 2007.

PD was taken as birth before the completion of 37 weeks. Threatening PD included obstetric events during pregnancy such as premature rupture of the membranes or treatment of uterine activity and/or cervical dilation. Patients with threatening PD received special obstetric treatment in order to maintain their pregnancy for as long as possible (oral or intravenous tocolysis, and antibiotic therapy in the event of current infection indicated by the microbiological results on vaginal samples). As a result of the treatment for threatening PD, labour could then possibly be delayed until after the 37 th week of gestation.

Professional Periodontal Treatment May

Prevent Preterm Delivery
The oral examination for group $\mathrm{A}$ and the examination and oral therapy for group B were performed as soon as possible after the hospitalization for threatening PD. The oral examinations were performed for the assessment of the periodontal status and the presence or absence of periodontitis. The PT methods involved supra- and subgingival scaling and polishing, using ultrasonic and manual instruments, plus instruction and motivation for better dental care. This therapy was provided in all 44 cases in group B. After the delivery, all of the patients from group A who met criteria for periodontitis during their pregnancies were treated in a similar way to the patients from group B.

Clinical periodontal status was defined on the basis of probing depth and bleeding on probing (BOP). Probing depth was measured with a disposable periodontal probe with a tip diameter of $0.5 \mathrm{~mm}$. Probing depth was not recorded on the third molars or on retained roots; it was measured at 6 sites per tooth: mesiobuccal, mid-buccal, distobuccal, mesiolingual, mid-lingual and distolingual sites. During the examination, BOP was also recorded at the sites where probing depth was measured, on the 'yes'/'no' scale.

As for the criteria of periodontitis, patients were categorized as having periodontitis if there was a pocket with a probing depth $\geq 4 \mathrm{~mm}$ at least found at 1 site, and BOP at $>50 \%$ of the dental sites. Participants without these criteria were classified as periodontally healthy.

\section{Statistical Analysis}

To compare continuous data between the two groups, we first checked the normal distribution of the data using the Kolmogorov-Smirnov test. As the data were found not to be normal, we used the Mann-Whitney $U$ test for a comparison. For categorical data, the $\chi^{2}$ and Fisher's exact tests were used.

\section{Results}

During the selection, 83 patients satisfied the inclusion criteria for this study: threatening $\mathrm{PD}$, in eligible primigravida-primipara healthy women with a singleton pregnancy.

As a consequence of the almost equal frequencies of periodontitis [ 19 cases in group A (48.7\%) vs. 18 cases in group B (40.9\%)], the two groups were comparable $(\mathrm{p}=$ $0.513)$. 
The mean maternal age at delivery was 25.7 years in group $A$ and 27.3 years in group $B$.

The mean gestational age and the mean newborn weights at delivery, the umbilical cord vein $\mathrm{pH}$ data and the rate of prematurity are presented in table 1 .

The mean gestational age at delivery was significantly higher in the PT group ( $\mathrm{p}=0.011)$.

In group $B$, the mean newborn weight was significantly higher than in group $A(p=0.007)$.

There was no significant difference between the 5-min Apgar scores of the newborns in the two groups ( $\mathrm{p}=$ 0.127). The $\mathrm{pH}$ of the umbilical cord sample at delivery was not significantly different in the two groups.

The rate of prematurity in group A $(53.8 \%, 21$ cases) was significantly higher than in group B $(25.0 \%, 11$ cases). The adjusted odds ratio (OR) for the term delivery in the case of treatment of periodontitis during pregnancy was 3.5 ( $95 \%$ confidence interval, $\mathrm{CI}=1.36-8.86, \mathrm{p}=$ 0.012). The adjusted $\mathrm{OR}$ for $\mathrm{PD}$ in this case was 0.286 lower $(95 \% \mathrm{CI}=0.113-0.723)$.

The same number of newborns was admitted to the Neonatal Intensive-Care Unit from group A $(n=10)$ and from group $B(n=10)$. The mothers of these newborns had periodontitis at the dental examination in 6 cases in group $\mathrm{A}$ and in 2 cases in group $\mathrm{B}$.

\section{Comment}

The present study has suggested an association between the periodontal status of mothers and PD in the south-east of Hungary. Professional PT, maternal motivation and oral hygiene instruction amongst pregnant women with or without periodontitis were effective in reducing the rate of $\mathrm{PD}$, and inducing a higher birth weight and consequently a better neonatal outcome.

Our previous data revealed that the most important periodontal factors associated with the pregnancy outcome, and especially $\mathrm{PD}$, are gingival bleeding and probing depth $\geq 4 \mathrm{~mm}$ at least found at 1 site. Thus, our findings may be explained by the strong association between $B O P$ and $P D$ [14].

Hormonal changes during pregnancy exert a special effect on the periodontium. The vascular permeability in the gingival tissue is increased, consequently bacteria and/or their products can diffuse into the tissues more readily than normal. Such bleeding during the active phase of periodontitis means that the sulcar epithelium is no longer intact, being more permeable to lipopolysaccharide, interleukin- $1 \beta$ and other bacterial products. Es- tablished periodontitis with probing depth $\geq 4 \mathrm{~mm}$ may translate into a gingival wound surface area of $10-20 \mathrm{~cm}^{2}$ which permits ready bacterial product penetration into the host tissues. Since such bleeding is an important sign of gingival inflammation, both probing depth and BOP were used to categorize the periodontal status [15].

Although the reports referred to the above studies and our own study may not provide sufficiently convincing scientific evidence (larger multi-centre trials would be required), PT in cases of periodontitis in pregnant women could be highly recommended. Since this therapy involves no risk, can be carried out easily and is relatively inexpensive, it could be advantageous when introduced systematically in the frame of pregnancy care. Of course it would be even better to provide PT as a preventive method when pregnancy is planned, and good oral health should be maintained throughout pregnancy. Since PD is the cause of perinatal mortality in most cases, all efforts that could result in a reduction of PD and perinatal morbidity and mortality are important. As a result of our findings, a special dentistry unit has been opened at the Department of Obstetrics and Gynaecology of the University of Szeged, the first in Hungary where patients treated for threatening PD undergo stomatological examinations and, if necessary, therapeutic recommendations are made. Popularization of periodontal preventive measures, before and during pregnancy, which can decrease the rate of $\mathrm{PD}$, is highly recommended.

\section{Acknowledgements}

This study was supported in part by project grant ETT (Scientific Research Fund in Hungary) 579/2000.

References

1 Offenbacher S, Katz V, Fertik G, Collins J, Boyd D, Maynor G: Periodontal infection as a possible risk factor for preterm low birth weight. J Periodontol 1996;67:1103-1113.

2 Gibbs RS: The relationship between infections and adverse pregnancy outcomes: an overview. Ann Periodontol 2002;6:153-163.

3 Hill GB: Preterm birth: associations with genital and possibly oral microflora. Ann Periodontol 1998;3:222-232.

4 Hillier SL, Witkin SS, Krohn MA, Watts DH, Kiviat NB, Eschenbach DA: The relationship of amniotic fluid cytokines and preterm delivery, amniotic fluid infection, histologic chorioamnionitis, and chorioamnion infection. Obstet Gynecol 1993;81:941-948. 
5 Jeffcoat MK, Geurs NC, Reddy MS, Oliver SP, Goldenerg RL, Hauth JC: Periodontal infection and preterm birth: results of a prospective study. J Am Dent Assoc 2001;132: 875-880.

6 McGaw T: Periodontal disease and preterm delivery of low-birth-weight infants. J Can Dent Assoc 2002;68:165-169.

7 Pithipat W, Joshipura KJ, Gillman MW, Wiliams PL, Douglass CW, Rich-Edwards JW: Maternal periodontitis and adverse pregnancy outcomes. Community Dent Oral Epidemiol 2008:36:3-11.

8 Lin D, Moss K, Beck JD, Hefti A, Offenbacher S: Persistently high levels of periodontal pathogens associated with preterm pregnancy outcome. J Periodontol 2007;78:883-841.
9 Boggess KA: Pathophysiology of preterm birth: emerging concepts of maternal infection. Clin Perinatol 2005;32:561-569.

10 Davenport ES, Williams CE, Sterne JC, Murad S, Sivapathasundram V, Curtis MA: Maternal periodontal disease and preterm low birth weight: case-control study. J Dent Res 2002;81:313-318.

11 López NJ, Smith PC, Gutierrez J: Periodontal therapy may reduce the risk of preterm low birthweight in women with periodontal dis. ease: a randomized controlled trial. J Periodontol 2002;73:911-924.
12 Dasanawake AP, Gennaro S, Hendricks Munoz KD, Chun N: Maternal periodontal disease, pregnancy, and neonatal outcomes. Am J Matern Child Nurs 2008;33:45-49.

13 Tarranum F, Faizuddin M: Effect of periodontal therapy on pregnancy outcome in women affected by periodontitis. J Periodontol 2007;78:2095-2103.

14 Radnai M, Gorzó I, Nagy E, Urbán E, Novák T, Pál A: A possible association between preterm birth and early periodontitis. I Clin Periodontol 2004;31:736-741.

15 Boggess KA: Is there a link between periodontal disease and preterm birth? Contemp Obstet Gynecol 2003;48:79-84. 